https://www.journal-imab-bg.org

Original article

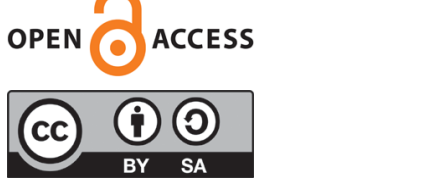

\title{
STUDY ON THE FREQUENCY OF TEETH BRUSHING FOR PATIENTS WITH TERMINAL STAGE OF CHRONIC KIDNEY DISEASE AND BEING ON CHRONIODIALYSIS, AND HEALTHY CONTROLS
}

\author{
Anna Nenova-Nogalcheva ${ }^{1}$, Desislava Konstantinova ${ }^{2}$, Petia Pechalova ${ }^{3}$ \\ 1) Department of Oral Surgery, Faculty of Dental Medicine, Medical University \\ - Varna, Bulgaria \\ 2) Department of Dental Materials Science and Propedeutics of Prosthetic Dental \\ Medicine, Medical University - Varna, Bulgaria \\ 3) Department of Oral Surgery, Faculty of Dental Medicine, Medical University \\ - Plovdiv, Bulgaria..
}

\begin{abstract}
Dentists usually recommend at least two minutes of brushing two times per day as a minimum.

The purpose of this study is to establish the frequency of teeth brushing for patients with terminal stage of chronic kidney disease and for healthy controls.

Materials and methods: 140 patients from Northeastern Bulgaria took informed participation, volunteering, in this study. They are separated into two groups - 70 people were diagnosed with terminal stage of chronic kidney disease (CKD) and chroniohemodialysis at different stages of disease duration and 70 healthy controls. Anamnestic and socio-demographic data were collected, about gender, age and frequency of teeth brushing. The result was statistically processed using the IBM SPSS Statistics software, Version 20.

Results: Data show that there is a statistically significant difference $\left(\chi^{2}=79,031, \mathrm{p}=0,000\right)$ between the patients of the groups studied. As we have expected, the patients from the control group brush their teeth more often (between 2 and 3 times per day).

The Mann-Whitney test with Bonferroni correction shows that the CKD patients brush their teeth daily less than the people from the control group. Statistically significant difference $(\mathrm{U}=1831,000, \mathrm{p}=0,004)$ is established between the two group participants.

Conclusion: The frequency of teeth brushing as a main factor for maintaining good personal oral hygiene is higher for the healthy controls in comparison to the patients under the study, who belong to the group of people with CKD. We need more studies in order to understand better how could the frequency of teeth brushing influence the limitation of oral problems for people with kidney diseases on chroniodialysis.
\end{abstract}

Keywords: oral hygiene, teeth brushing, patients with CKD, chroniodiaysis

\section{INTRODUCTION}

Tooth brushing is the most common instrument for the control of dental plaque and of essential importance for its removal [1]. The toothbrush may remove the subgingival plaque on the teeth, and other helpful means (such as dental floss, interdental toothbrushes, irrigators, etc.) are recommended for cleaning the interproximal space [2]. Dentists usually recommend at least two minutes of brushing two times per day as a minimum [3]. The 2016 systematical review of Kumar et al. evidence that the frequency of teeth brushing is related to the level of maintaining good oral health [4]. Studies on this subject establish that patients who brush their teeth more rarely have more dental caries present [5].

Other scientists confirm that the regular teeth brushing results in significant decreasing of the risk of teeth loss [6]. The accumulation of dental plaque on teeth surface can be the initiating factor for many diseases and conditions, which have an impact on the patients. Paradontal diseases, including gingivitis and periodontal disease, are widely distributed in the global aspect and are a health problem for the entire population [7]. Accumulation of supra- and subgingival plaque is the most important risk factor for the development of paradontal diseases, as well as for dental caries $[8,10]$. Therefore, their accumulation prevention and gingivitis treatment should be considered as a main preventive strategy for paradontosis $[8,9]$.

The scientific literature shows studies that demonstrate the connection between unsatisfactory dental status and prevailing cardo-vascular disease for patients on supporting chroniohemodialysis, and between advanced periodontal disease and left ventricular hypertrophy for recipients on kidney transplant $[11,12]$.

The matter about the paradontal disease for patients with renal failure is only slightly mentioned in the nephrological literature $[13,14]$. 
The purpose of this study is to establish the frequency of teeth brushing for patients with terminal stage of chronic kidney disease and for healthy controls.

\section{MATERIALS AND METHODS}

Seventy patients from Northeastern Bulgaria took informed participation, volunteering, in this study, as they were diagnosed with terminal stage of chronic kidney disease and chroniohemodialysis at different stages of disease duration. The people included in this study were of age between 32 and 89 years. The average age of the people under this study was $60,66 \pm 14,46$ years.
32 men $(45,7 \%)$ and 38 women $(54,3 \%)$. The healthy controls were of the same region, age of 19 , also 70 people. Anamnestic and socio-demographic data were collected, about gender, age and frequency of teeth brushing.

Information was statistically processed using the IBM SPSS Statistics software, Version 20.

\section{RESULTS}

Data analysis about the frequency of daily teeth brushing for the patients under the study, per gender and group, are shown in the below Table 1 .

Table 1. Frequency and percentage distribution per gender and groups

\begin{tabular}{|c|c|c|c|c|c|c|c|c|c|c|c|c|}
\hline \multirow{4}{*}{$\begin{array}{l}\text { Daily teeth } \\
\text { brushing }\end{array}$} & \multicolumn{12}{|c|}{ Groups } \\
\hline & \multicolumn{6}{|c|}{ CKD Patients } & \multicolumn{6}{|c|}{ Control Group } \\
\hline & \multicolumn{2}{|c|}{ Men } & \multicolumn{2}{|c|}{ Women } & \multicolumn{2}{|c|}{ Total } & \multicolumn{2}{|c|}{ Men } & \multicolumn{2}{|c|}{ Women } & \multicolumn{2}{|c|}{ Total } \\
\hline & No & $\%$ & No & $\%$ & No & $\%$ & No & $\%$ & No & $\%$ & No & $\%$ \\
\hline Once & 8 & 11,4 & 6 & 8,6 & 14 & 20 & 5 & 7,1 & 3 & 4,3 & 8 & 11,4 \\
\hline Twice & 20 & 28,6 & 23 & 32,9 & 43 & 61,4 & 19 & 27,1 & 14 & 20 & 33 & 47,1 \\
\hline Three times & 4 & 5,7 & 9 & 12,9 & 13 & 18,6 & 15 & 21,4 & 14 & 20 & 29 & 41,4 \\
\hline
\end{tabular}

The results show that 9 women and only four men of the participants with CKD are brushing their teeth three times a day. The detailed analysis in this group demonstrates that almost one-third of the women $(32,9 \%)$ brush their teeth twice a day, and the men of the same group brushing their teeth two times a day are $28,60 \%$.

As for the control group - 15 men and 14 women are brushing their teeth three times a day, which is about one-fifth of the group, in both cases. One-fifth of the women $(20 \%)$ brush their teeth twice a day as well, and about one-third of men $(27,10 \%)$ clean their teeth two times a day.

The distribution per age and frequency of teeth brushing for the three groups of patients is also interesting. (Table 2)

Table 2. Frequency and percentage distribution as per the daily teeth brushing per age and groups

\begin{tabular}{|c|c|c|c|c|c|c|c|c|c|c|c|c|}
\hline \multirow{4}{*}{$\begin{array}{l}\text { Daily teeth } \\
\text { brushing }\end{array}$} & \multicolumn{12}{|c|}{ Groups } \\
\hline & \multicolumn{6}{|c|}{ CKD Patients } & \multicolumn{6}{|c|}{ Control Group } \\
\hline & \multicolumn{2}{|c|}{$19-32$} & \multicolumn{2}{|c|}{$33-90$} & \multicolumn{2}{|c|}{ Total } & \multicolumn{2}{|c|}{$19-32$} & \multicolumn{2}{|c|}{$33-90$} & \multicolumn{2}{|c|}{ Total } \\
\hline & No & $\%$ & No & $\%$ & No & $\%$ & No & $\%$ & No & $\%$ & No & $\%$ \\
\hline Once & 1 & 1,4 & 13 & 18,6 & 14 & 20 & 8 & 11,4 & 0 & 0 & 8 & 11,4 \\
\hline Twice & 2 & 2,9 & 41 & 58,6 & 43 & 61,4 & 33 & 47,1 & 0 & 0 & 33 & 47,1 \\
\hline Three times & 1 & 1,4 & 12 & 17,1 & 13 & 18,6 & 29 & 41,4 & 0 & 0 & 29 & 41,4 \\
\hline
\end{tabular}

The general analysis of the results for the CKD patients group shows that the participants of middle and elderly age (33 -90 years) brush their teeth more often $(58,60$ $\%$ patients -two times). Only $1.40 \%$ of the patients of younger age with kidney disease brush their teeth once per day, and 2,90\% - twice per day.

The control group consists of only young people. It could be seen that the young people of this group choose to brush their teeth mainly two times a day $(47,10 \%)$ or three times a day $(41,40 \%)$.

As expected, most of the people from the control group brush their teeth after each meal (29 people, 41, $40 \%$ ), and almost half of the health controls brush their teeth twice a day $(47,10 \%)$. This precondition, together with the lack of senile changes, body's compensatory capabilities, etc., result in a good oral status of the control group representatives.

The above Tables 1 and 2, show that the distribution of the variables studies is not normal. That demanded the use of the non-parametric test for differences between more than two groups, as per Kruskal-Wallis Test, as verification of the statistic differences between the two groups. The analysis of the results from this test, according to the "number of teeth brushing per day" criterion, states statistically significant differences between the groups (Table 3). 
Table 3. Results from the Kruskal-Wallis test for statistical differences between the groups

\begin{tabular}{lcccc}
\hline Group & N & Average Rank & $\boldsymbol{\chi}^{\mathbf{2}(\mathbf{d f})}$ & $\mathbf{P}$ \\
CKD Patients & 70 & 117,74 & & \\
Control Group & 70 & 140,36 & $79,031(2)$ & 0 \\
\hline
\end{tabular}

Data show that there is a statistically significant difference $\left(\boldsymbol{\chi}^{\mathbf{2}}=\mathbf{7 9 , 0 3 1}, \mathbf{p}=\mathbf{0 , 0 0 0}\right)$ between the patients of the groups studied. As we have expected, the patients from the control group brush their teeth more often (between 2 and 3 times per day).

For the purposes of more detailed analysis, we have applied the Mann-Whitney Test with Bonferroni correction. The results show that the CKD patients brush their teeth daily less than the people from the control group. Statistically significant difference $(\mathrm{U}=1831,000, \mathrm{p}=$ $0,004)$ is established between the two group participants.

\section{DISCUSSION}

The indirect, however convincing proof that confirmed the importance of the oral hygiene is derived from a study evidencing that the subgingival curettage and the professional oral hygiene combined with locally applied anti-microbe means have a favourable effect on some cardio-vascular risk factors for healthy patients with periodontitis [15].

According to the number of times for teeth brushing per day, the patients with accompanying kidney disease demonstrate following the instructions given by the dentist in regard to the personal oral hygiene. It is established that more than half of the people $(47,10 \%)$ brush their teeth twice per day as per the recommendations. The participants from the control group are young people (19 years of age), with high requirements on their appearance and personal hygiene, incl. personal oral hygiene. They are very well aware of the novelties in dental cosmetics, as well as the different means and techniques for maintaining good oral health. This is most probably the reason for their high motivation to brush their teeth after every meal ( 2 to 3 three times per day).

L. Locsey et al. (1986), Chuang et al. (2005) speak in their studies about the early loss of teeth for patients on hemodialysis in comparison to the general population $[16,17,18,19,20,21,22]$. Due to the connection of the main disease with several specific oral problems and in order to obtain more detailed results in future, the further studies need to analyze the power of brushing, the techniques of brushing between the left and right side, and use of additional means for personal oral hygiene (dental floss, interdental brushes, etc.).

\section{CONCLUSION}

The frequency of teeth brushing as a main factor for maintaining good personal oral hygiene is higher for the health controls in comparison to the patients under the study, who belong to the group of people with CKD. Although, the people from that group also show satisfactory frequency of teeth brushing (in most cases 2 times per day); probably following the instructions of their dentist.

We need more studies in order to understand better how could the frequency of teeth brushing influence the limitation of oral problems for people with kidney diseases on chroniodialysis.

\section{REFERENCES:}

1. Ganss C, Schlueter N, Preiss S, Klimek J. Tooth brushing habits in uninstructed adults-frequency, technique, duration and force. Clin Oral Investig. 2009 Jun;13(2):203-8. [PubMed] [Crossref]

2. Worthington HV, MacDonald L, Pericic TP, Sambunjak D, Johnson TM, Imai P, et al. Home use of interdental cleaning devices, in addition to toothbrushing, for preventing and controlling periodontal diseases and dental caries. Cochrane Database Syst Rev. 2019 Apr 10;4(4): CD012018. [PubMed] [Crossref]

3. Van der Weijden GA , Timmerman MF, Nijboer A, Lie MA, Van der Velden U. A comparative study of electric toothbrushes for the effectiveness of plaque removal in relation to toothbrushing duration. Timerstudy. J Clin Periodontol. 1993

\section{Aug;20(7):476-81 [PubMed]}

4. Kumar S, Tadakamadla J, Johnson NW. Effect of Toothbrushing Frequency on Incidence and Increment of Dental Caries: A Systematic Review and Meta-Analysis. J Dent Res. 2016 Oct;95(11):1230-6. [PubMed]

5. Sutcliffe P. Oral cleanliness and dental caries. In: The Prevention of Oral Disease. 3rd Edition. Murray JJ. (Editor). Oxford University Press. July 11, 1996. pp.68-77.

6. Hujoel P. Consistent brushing may save teeth. J Evid Based Dent Pract. 2003 Dec;3(4):202-203. [Crossref]

7. Petersen PE, Ogawa H. The global burden of periodontal disease: towards integration with chronic disease prevention and control. Periodontol 2000. 2012 Oct;60(1):15-39.
[PubMed] [Crossref]

8. Chapple ILC, Van der Weijden F, Doerfer C, Herrera D, Shapira L, Polak D, et al. Primary prevention of periodontitis: managing gingivitis. $J$ Clin Periodontol. 2015 Apr;42 Suppl 16:S71-6. [PubMed] [Crossref]

9. Kinane DF, Attstrom R, EWP group B. Advances in the pathogenesis of periodontitis. Group B consensus report of the fifth European Workshop in Periodontology. $J$ Clin Periodontol. 2005; 32 Suppl 6:130-1. [PubMed] [Crossref]

10. Kassebaum NJ, Smith AGC, Bernabe E, Fleming TD, Reynolds AE, Vos T, et al. Global, Regional, and National Prevalence, Incidence, and Disability-Adjusted Life Years for Oral Conditions for 195 Countries, 19902015: A Systematic Analysis for the Global Burden of Diseases, Injuries, 
and Risk Factors. J Dent Res. 2017

Apr;96(4):380-387. [PubMed] [Crossref]

11. Borawski J, WilczynskaBorawska M, Stokowska W, Mysliwiec M. The periodontal status of pre-dialysis chronic kidney disease and maintenance dialysis patients. Nephrol Dial Transplant. 2007 Feb; 22(2):457-64. [PubMed] [Crossref]

12. Franek E, Blach A, Witula A, Kolonko A, Chudek J, Drugacz J, et al. Association between chronic periodontal disease and left ventricular hypertrophy in kidney transplant recipients. Transplantation. $2005 \mathrm{Jul}$ 15;80(1):3-5. [PubMed]

13. Rahmati MA,Craig RG,Homel P, Kaysen G, Levin NW. Serum markers of periodontal disease status and inflammation in hemodialysis patients. Am J Kidney Dis. 2002 Nov; 40(5):983-9. [PubMed]

14. Chen L-P, Chiang C-K, Chan C-P, Hung K-Y, Huang C-S. Does periodontitis reflect inflammation and malnutrition status in hemodialysis patients? Am J Kidney Dis. 2006 May;47(5):815-22. [PubMed]

15. D'Aiuto F, Parkar M, Nibali L, Suvan J, Lessem J, Tonetti MS. Periodontal infections cause changes in traditional and novel cardiovascular risk factors: results from a randomized controlled clinical trial. Am Heart J. 2006 May;151(5):977-84. [PubMed] [Crossref]

16. Locsey L, Alberth M, Mauks G. Dental management of chronic haemodialysis patients. Int Urol Nephrol. 1986; 18(2):211-3. [PubMed]

17. Chuang S-F, Sung J-M, Kuo SC, Huang J-J, Lee S-Y. Oral and dental manifestations in diabetic and nondiabetic uremic patients receiving hemodialysis. Oral Surg Oral Med Oral Pathol Oral Radiol Endod. 2005 Jun;99(6):689-95. [PubMed]

18. Costantinides F, Castronovo G, Vettori E, Costanza Frattini C, Artero ML, Bevilacqua L, et al. Dental Care for Patients with End-Stage Renal Disease and Undergoing Hemodialysis. Int J Dent. 2018 Nov 13; 2018:

\section{2. [PubMed]}

19. Nylund K, Meurman JH, Heikkinen AM, Honkanen E, Vesterinen M, Ruokonen H. Oral health in predialysis patients with emphasis on periodontal disease. Quintessence Int. 2015 Nov-Dec; 46(10):899907. [PubMed]

20. Schmalz G, Kollmar O, Vasko R, Müller GA, Haak R, Ziebolz D. Oral health-related quality of life in patients on chronic haemodialysis and after kidney transplantation. Oral Dis. 2016 Oct;22(7):66572. [PubMed] [CrossRef]

21. Reyes U, Spolarich AE, Han PP. A Comprehensive oral preventive care protocol for caring for the renal transplant population. J Dent Hyg. 2016 Apr;90(2):88-99. [PubMed]

22. Baker RJ, Mark PB, Patel RK, Stevens KK, Palmer N. Renal association clinical practice guideline in post-operative care in the kidney transplant recipient. BMC Nephrol. 2017 Jun 2;18(1):174. [PubMed]

Please cite this article as: Nenova-Nogalcheva A, Konstantinova D, Pechalova P. Study on the frequency of teeth brushing for patients with terminal stage of chronic kidney disease and being on chroniodialysis, and healthy controls. $J$ of IMAB. 2020 Oct-Dec;26(4):3481-3484. DOI: https://doi.org/10.5272/jimab.2020264.3481

\author{
Address for correspondence: \\ Anna Nenova-Nogalcheva \\ Department of Oral Surgery, Medical University - Varna, Bulgaria \\ 84, Tsar Osvoboditel str., Varna, Bulgaria \\ E-mail: anenova@yahoo.com
}

